\section{A dynamic quintet}

Michael Shlesinger

Journal of Nonlinear Science. Editorsin-chief E. Kuznetsov and S. Wiggins. Springer. 4/yr. \$215 (institutional), \$65 (personal). (Includes subscription to Nonlinear Science Today.)

Nonlinear Science Today. Editorsin-chief P. Holmes and 1. Stewart. Springer. 4/yr. \$29.

Chaos, Solitons and Fractals: Applications in Science and Engineering. Editor-in-chief M. S. El Naschie. Pergamon. 6/yr. £320, $\$ 741$ (institutional).

Chaos. Editor-in-chief D. K. Campbell. AIP. 4/yr. US \$190, Europe and Asia $\$ 205$, elsewhere $\$ 195$ (institutional); $\$ 60$ (personal); US \$55, Europe and Asia $\$ 70$, elsewhere $\$ 60$ (members).

International Journal of Bifurcation and Chaos. Editor L. O. Chua. World Scientific. 6/yr. $\$ 380$ (institutional), $\$ 165$ (personal, and institutions/libraries from developing countries).

As recently as the late 1970 s, the best source of new work in nonlinear dynamics was Joe Ford's updated collection of preprint abstracts, which he mailed from Georgia Institute of Technology as a service to the community. This source eventually grew into the first nonlinear dynamics physics journal, Physica $D$, which was launched in 1980 . Before the advent of specialized nonlinear dynamics journals, seminal works appeared in a variety of journals. The masterpieces from E. Lorenz, D. Ruelle and F. Takens, R. M. May, and M. Feigenbaum appeared in Journal of Atmospheric Sciences, Communications in Mathematical Physics, Nature and Journal of Statistical Physics respectively. Since the inaugural issue of Physica $D$, other new journals, including Nonlinearity (reviewed in these pages two years ago), have appeared that are devoted to nonlinear dynamics, and many of the established journals, such as Physical Review Letters, also attract a steady stream of papers on the subject. It is a testament to the excitement and robust health of this discipline that four new high-quality journals and a magazine have recently joined this list. Ironically, with these new journals, we have come back full circle to the pre-1980 question of where to publish a nonlinear dynamics paper.

What audiences could these journals be trying to reach? Mathematicians, physicists, chemists, engineers, Earth scientists, biologists? Almost by definition, based on the universality of nonlinear equations and phenomena, the answer must be the same for each journal - all the above. For example, and flavour. community. period doubling, chaos, crises and strange nonchaotic attractors can be found in a wide variety of mathematical equations, physical phenomena, engineering applications and, perhaps, biological activity. Each journal wants to be the forum where different disciplines meet and interdisciplinary research based on nonlinear dynamics and fractals becomes a reality. Each journal does,

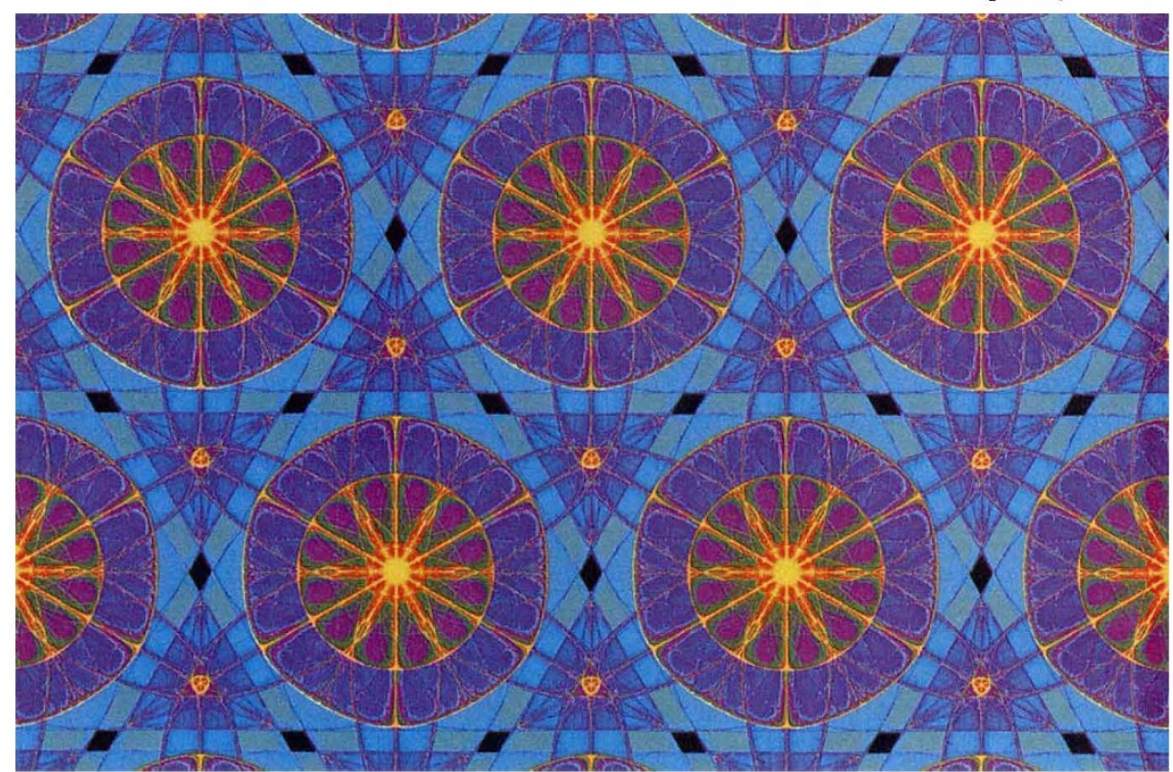

Sundlal mosaic - repeating pattern based on a hexagonal lattice. (The plcture is reproduced from Symmetry in Chaos by $\mathbf{M}$. Fleld and M. Golubltsky, published by Oxford Unlversity Press on 5 November and to be reviewed in a future issue of Nature. Price £19.95.)

however, have its own identifiable focus

Journal of Nonlinear Science should attract manuscripts of a more mathematical nature. But the editors insist that its papers go beyond the specific confines of the problem at hand and paint a broader picture, with physical concepts and experimental evidence directly addressed, so at least the introduction of each paper is worth reading. Its companion publication, Nonlinear Science Today, is inexpensive and just plain fun to read. It is more of a magazine, with interviews, tutorial articles, reviews, opinions and announcements. It is for leisure reading and keeps one in touch with the

Chaos, Solitons and Fractals, with its emphasis on applications, should find its natural home in the engineering community. It has the opportunity to play a pivotal role in bringing this new mindset to a community that has been slow to embrace the new paradigm of chaos. The journal has also attracted some good physics papers. There is a limited use of colour (free to authors), but the camera-ready format sometimes gives journal and the papers is very high.

The International Journal of Bifurcation and Chaos is the most handsomely produced, with its large pages and type, and it is the place to publish colour figures. The covers are breathtaking and the articles are rich with brilliant colour pictures (again free to authors). When lack of shelf space forces the clearing of my office some years from now, I shall hesitate to throw out any of these issues. Each begins with valuable tutorials and reviews, and is followed by papers and letters. It is evident that much effort has been expended to bring high-quality readable papers from a variety of scientific fields into this quarterly publication. Not just in terms of its low cost, I consider this journal the best buy.

With these five new publications (and their large editorial boards), it is clear that nonlinear dynamics has established itself as a dominant force in science. I await future issues with anticipation.

Michael Shlesinger is in the Division of Physics, Office of Naval Research, 800 North Quincy Street, Arlington, Virginia 22217-5000, USA. the journal the appearance of lecture notes rather than an archive of scholarly articles.

Chaos wants to be the home for papers communicating the advances of the great Russian school of dynamics. It will even accept manuscripts written in Russian. Chaos can play a valuable role in joining the US and Russian communities and in decreasing the re-invention of work that has often occurred among workers in the East and West. The journal is directed towards physicists and has made an excellent start towards attaining its goals. The quality of the 